\title{
Project Title: Fission-Product Separation Based on Room-Temperature Ionic Liquids
}

(OR08SP24-16)

Publication Date: Sept. 30, 2005

Principal Investigators:

Huimin Luo

Nuclear Science and Technology Division

Oak Ridge National Laboratory

Oak Ridge, TN 37831-6229

Tel: (865)-574-6228

E-mail: $\underline{\text { luoh@ornl.gov }}$

Collaborated with:

Sheng Dai

Peter V. Bonnesen

A. C. Buchanan III

R. D. Rogers

Charles L. Hussey

Department of Chemistry

The University of Mississippi

University, MS 38677

Tel: (662)-915-7301

E-mail: chclh@chem1.olemiss.edu

Annual Progress Report:

\section{Research Objective}

The objectives of this project are (a) to synthesize new ionic liquids tailored for the extractive separation of $\mathrm{Cs}^{+}$and $\mathrm{Sr}^{2+}$; (b) to select optimum macrocyclic extractants through studies of complexation of fission products with macrocyclic extractants and transport in new extraction systems based on ionic liquids; (c) to develop efficient processes to recycle ionic liquids and crown ethers; and (d) to investigate chemical stabilities of ionic liquids under strong acid, strong base, and high-level-radiation conditions.

\section{Research Progress and Implications}

This report summarizes research for the first year of a 3-year project. A series of immidazolium based ionic liquids with different anions were synthesized and characterized. The anions of the ILs under investigation here are hexafluorophosphate $\left(\mathrm{PF}_{6}^{-}\right)$, bis[(trifluoromethyl)sulfonyl]imide $\left(\mathrm{NTf}_{2}^{-}\right)$, and bis(perfluoroethanesulfonyl)imide $\left(\mathrm{BETI}^{-}\right)$. The order of hydrophobicity is $\mathrm{BETI}^{-}>\mathrm{NTf}_{2}{ }^{-}>\mathrm{PF}_{6}{ }^{-}$, which is consistent with the decreasing trend of the Connolly solvent-excluded volumes, $187.9 \AA^{3}, 136.6 \AA^{3}$, and $133.4 \AA^{3}$, respectively. The IL cations studied include 1- $\mathrm{C}_{n}$-3-methylimidazolium, where $\mathrm{C}_{n}=$ ethyl, butyl, hexyl, or octyl, and all of the ILs are known to be immiscible with water. Basic IL property data, including density and mutual solubilities with water, are shown in Table 1.

The solubilities of the different ILs as influenced by their anions were investigated by determining the equilibrium concentrations of the partitioned IL cations in aqueous solutions via UV spectroscopy. Figure 1 shows the UV spectra of $\mathrm{C}_{4} \mathrm{mim}^{+}$cation in water equilibrated with three ILs. As can be seen clearly, the solubilities of the ILs depend strongly upon the IL anion employed (subject to the condition of charge neutrality). The quantitative results are summarized in Table 1, showing that for the same cation, the solubility of an IL decreases with increased hydrophobicity of its anion. The loss of $\left[\mathrm{C}_{4} \mathrm{mim}\right][\mathrm{BETI}]$ through partitioning into water may be seen to be about 25 -fold less than that of $\left[\mathrm{C}_{4} \mathrm{mim}\right]\left[\mathrm{PF}_{6}\right]$. Water partitioning into the ILs also decreases with IL anion hydrophobicity. Accordingly, the hydrophobicity of the IL anion is a key factor determining the mutual solubilities of an IL and water. 
Table 1. Effect of Different IL Anions on Water Content and Solubility of ILs in Water

\begin{tabular}{cccccc}
\hline & \multicolumn{2}{c}{$\left[\mathrm{C}_{2}\right.$ mim $][\mathrm{X}]$} & \multicolumn{3}{c}{$\left[\mathrm{C}_{4}\right.$ mim $][\mathrm{X}]$} \\
\cline { 2 - 6 } & $\mathrm{NTf}_{2}^{-}$ & $\mathrm{BETI}^{-}$ & $\mathrm{PF}_{6}^{-}$ & $\mathrm{NTf}_{2}^{-}$ & $\mathrm{BETI}^{-}$ \\
\hline Density $(\mathrm{g} / \mathrm{mL})$ & 1.50 & 1.53 & 1.37 & 1.42 & 1.45 \\
$\mathrm{H}_{2} \mathrm{O}$ content in & 350 & 223 & 513 & 240 & 143 \\
"dry" ILs (ppm) & 19400 & 10600 & 20700 & 13600 & 7070 \\
$\begin{array}{c}\mathrm{H}_{2} \mathrm{O} \text { content in } \\
\text { wet* ILs (ppm) }\end{array}$ & 45.3 & 8.93 & 86.6 & 19.0 & 3.41 \\
$\begin{array}{c}\mathrm{IL} \text { solubility in } \\
\mathrm{H}_{2} \mathrm{O}(\mathrm{mM})\end{array}$ & & & & & \\
\hline
\end{tabular}

*1 $\mathrm{mL}$ of ionic liquid was contacted with $10 \mathrm{~mL}$ of $\mathrm{H}_{2} \mathrm{O}$ for one hour.

Table

presents the results for $\mathrm{Cs}^{+}$and $\mathrm{Sr}^{2+}$ extraction by $0.1 \mathrm{M}$ DCH18C6 in nine ILs. Experiments were performed as single-species (i.e., noncompetitive) extractions from either $\mathrm{SrCl}_{2}$ or $\mathrm{CsCl}$ aqueous solution. It is clear from Table 2 that the distribution ratios for both $\mathrm{Sr}^{2+}$ and $\mathrm{Cs}^{+}$ increase markedly with the hydrophobicity of the IL anions for the same IL cation. A large increase (over 2 orders of magnitude) in the $D_{\mathrm{Sr}}$ value can be induced by changing the IL anion from $\mathrm{PF}_{6}{ }^{-}$ to $\mathrm{BETI}^{-}$. Although an increase in $D_{\mathrm{Cs}}$ also occurs, it is smaller than that of $D_{\mathrm{Sr}}$. The increase in $D_{\mathrm{M}}$ with increasing IL anion hydrophobicity contrasts sharply with the decrease in $D_{\mathrm{M}}$ observed with increasing IL cation hydrophobicity as measured by the imidazolium $\mathrm{C}_{n}$ chain length.

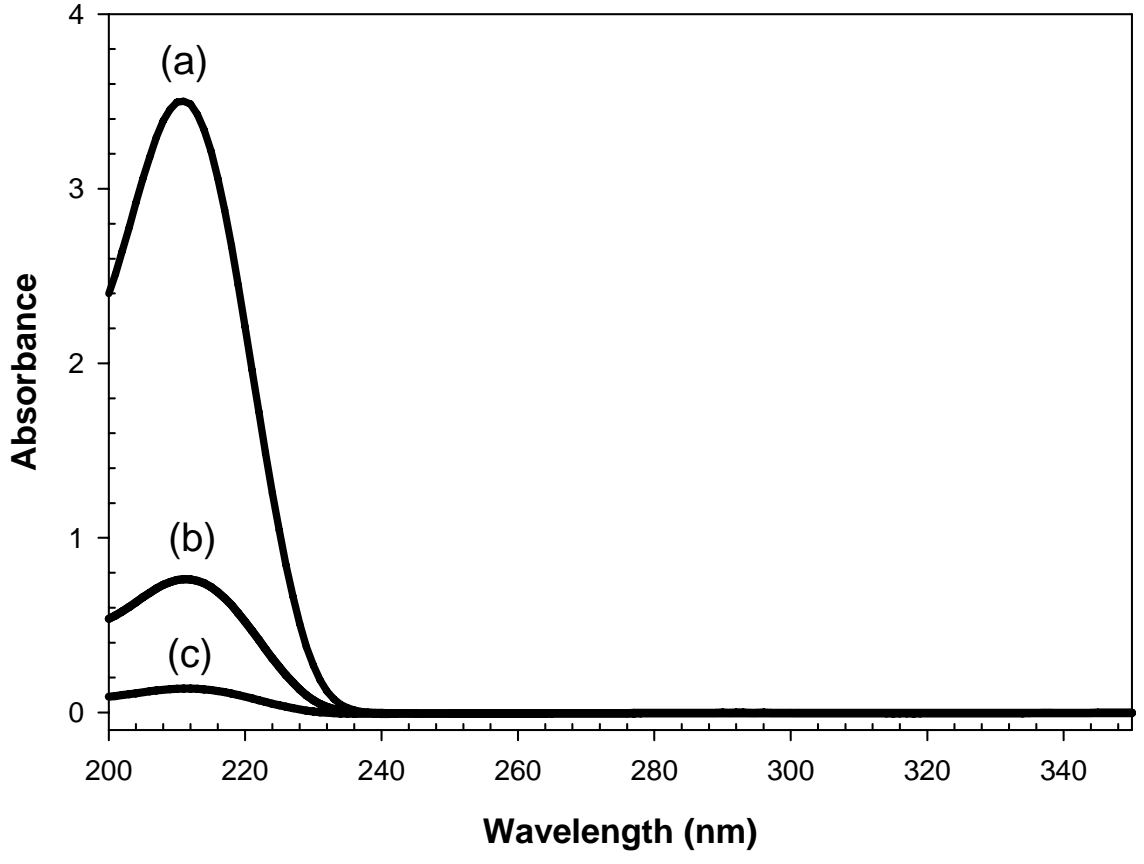

Figure 1. Determination of imidizolium concentration in water of (a) $\left[\mathrm{C}_{4} \mathrm{mim}\right]\left[\mathrm{PF}_{6}\right]$, (b) $\left[\mathrm{C}_{4} \mathrm{mim}\right]\left[\mathrm{NTf}_{2}\right]$, and (c) $\left[\mathrm{C}_{4} \mathrm{mim}\right][\mathrm{BETI}]$ via $\mathrm{UV}$-vis spectra of equilibrium aqueous phases. 
Table 2. Effect of Different IL Anions on Extraction Strength*

\begin{tabular}{|c|c|c|c|c|c|c|c|c|c|}
\hline \multirow[t]{2}{*}{$\begin{array}{l}\text { Aqueous } \\
\text { Phase } \\
(1.5 \mathrm{mM})\end{array}$} & \multicolumn{2}{|c|}{$\begin{array}{c}D_{\mathrm{M}} \\
{\left[\mathrm{C}_{2} \operatorname{mim}\right][\mathrm{X}]}\end{array}$} & \multicolumn{3}{|c|}{$\begin{array}{c}D_{\mathrm{M}} \\
{\left[\mathrm{C}_{4} \operatorname{mim}\right][\mathrm{X}]}\end{array}$} & \multicolumn{2}{|c|}{$\begin{array}{c}D_{\mathrm{M}} \\
{\left[\mathrm{C}_{6} \mathrm{mim}\right][\mathrm{X}]}\end{array}$} & \multicolumn{2}{|c|}{$\begin{array}{c}D_{\mathrm{M}} \\
{\left[\mathrm{C}_{8} \mathrm{mim}\right][\mathrm{X}]}\end{array}$} \\
\hline & $\mathrm{NTf}_{2}^{-}$ & $\mathrm{BETI}^{-}$ & $\mathrm{PF}_{6}^{-}$ & $\mathrm{NTf}_{2}^{-}$ & $\mathrm{BETI}^{-}$ & $\mathrm{NTf}_{2}^{-}$ & $\mathrm{BETI}^{-}$ & $\mathrm{NTf}_{2}{ }^{-}$ & $\mathrm{BETI}^{-}$ \\
\hline $\mathrm{CsCl}$ & 589 & 1140 & 56.9 & 380 & 567 & 66.0 & 151 & 8.35 & 25.7 \\
\hline $\mathrm{SrCl}_{2}$ & 10700 & 79700 & 18.3 & 935 & 3950 & 82.2 & 127 & 3.95 & 6.89 \\
\hline
\end{tabular}

*Single-species extraction (non-competitive conditions); 0.10 M DCH18C6 in each IL; IL/aqueous phase ratio $=0.1 ; T=21{ }^{\circ} \mathrm{C}$.

We propose that the IL anion effect originates from a combination of mass-action and solvation phenomena. The ability of the IL to solvate extracted metal species may be expected to depend upon the character of both the cation and anion used in the IL. One at first looks to such a dependency as a logical explanation of the influence of IL anion seen in Table 2. However, given that the cation-exchange mechanism has been shown to dominate, at least for the case of strontium and $n \leq 6$, it is also apparent that the driving force for extraction should be weakened by the mass-action effect of an increased concentration of IL cation present in the aqueous phase due to the IL solubility therein. Because the IL solubility in water increases with decreasing IL anion hydrophobicity, one may appreciate that this mass-action effect must play a significant role in the overall IL anion hydrophobicity effect. As the mass-action effect is straightforward to evaluate, it then becomes possible to judge the importance of the solvation effect.

From prior results, the basic cation-exchange mechanism involving crown ethers in ILs can be written as follows:

$\mathrm{M}^{q+}(\mathrm{aq})+\mathrm{CE}(\mathrm{IL})+q \mathrm{C}_{n} \operatorname{mim}^{+}(\mathrm{IL}) \rightleftharpoons \mathrm{M}^{q+} \mathrm{CE}(\mathrm{IL})+q \mathrm{C}_{n} \operatorname{mim}^{+}(\mathrm{aq})$

where $\mathrm{M}^{q+}, \mathrm{CE}$, and $\mathrm{C}_{n} \mathrm{mim}^{+}$are metal ion, crown ether, and imidazolium ion, respectively. The application of Le Chatelier's principle to eq. (1) indicates that as the the concentration of $\mathrm{C}_{n} \mathrm{mim}^{+}$ in the aqueous phase increases due to the solubility of the IL in the aqueous phase, cation exchange will be opposed and extraction weakened. In the experiments conducted here with $\mathrm{C}_{2} \mathrm{mim}^{+}$and $\mathrm{C}_{4} \mathrm{mim}^{+}$, the concentration of $\mathrm{C}_{n} \mathrm{mim}^{+}$in aqueous solution results mainly from the solubility of the ILs in the aqueous phases, as the concentration of $\mathrm{C}_{n} \mathrm{mim}^{+}$added by cation exchange (i.e., approximately the initial concentration of metal ion in the aqueous phase) is small by comparison.

\section{Planned Activities}

With the continued support of the DOE-EMSP program, we will complete studies needed to turn the promising results achieved to date into advanced solvent systems that can be effectively employed for the separation of fission products from high-level tank wastes. The studies will be aimed at: (1)development of ionic liquid solvents that are stable in highly caustic solutions and which have enhanced extraction efficiency and selectivity for $\mathrm{Sr}^{2+}$ and $\mathrm{Cs}^{+},(2)$ synthesis of recylclable aza-substituted calixarene crown ethers for selective separation of $\mathrm{Cs}^{+}$in ionic liquids and new task-specific regenerable ionic liquids tailored for the extractive separation of $\mathrm{Sr}^{2+}$, (3)investigation of sacrificial ion-exchange processes to enhance extraction efficiency and reduce the loss of ionic liquids, (4)development of electrochemical regeneration of ionic liquids loaded with fission products for exceptional volume reduction, (5)investigation of the stabilities 
of ionic liquids under aggressive chemical and high-level radiation conditions. We believe that this work will lead to the discovery and development of a new and very versatile class of solvent systems that will improve processes for separation of fission products by reducing hazards and process complexity.

\section{Information Access}

- Luo, H.; Dai S.; Bonnesen, P. V.; Haverlock, T. J.; Moyer, B. A.; and A. C. Buchanan III "A Striking Effect of Ionic-Liquid Anions in the Extraction of $\mathrm{Sr}^{2+}$ and $\mathrm{Cs}^{+}$by Dicyclohexano-18-Crown-6" Solvent Extr. Ion Exch. 2005, in press.

- Huang, J. F.; Luo, H.; Liang, C.; Sun, I. W.; and Dai, S. "Hydrophobic Bronsted AcidBase Ionic Liquids Based on PAMAM Dendrimers with High Proton Conductivity and Blue Photoluminescence" J. Am. Chem. Soc. 2005, in press.

- Lee, B.; Luo, ; Yuan, C. Y.; Lin, J. S.; and Dai, S. "Synthesis and characterization of organic-inorganic hybrid mesoporous silica materials with new templates" Chem. Comm. 2004, 240-241.

- Luo, H.; Dai, S.; Bonnesen, P. V.; Buchanan, A. C. III "Seperation of Fission Products Based On Ionic Liquids: Task-Specific Ionic Liquids Containing An Aza-Crown Ether Fragment" $24^{\text {th }}$ Rare Earth Research Conference, Keystone, Colorado, June 25-30, 2005. 